\title{
Fever induced by isoniazid
}

\author{
Pinar Tosun Tasar ${ }^{1 *}$, Sevnaz Sahin ${ }^{1}$, Niyazi Bozkurt ${ }^{2}$, Abdullah Sayıner $^{3}$, Soner Duman ${ }^{2}$, \\ Fehmi Akcicek ${ }^{1}$ \\ ${ }^{1}$ Division of Geriatrics, Department of Internal Medicine, Faculty of Medicine, Ege University, Izmir, Turkey; \\ *Corresponding Author: pinar.tosun@gmail.com, drsevnaz@hotmail.com, fehmi.akcicek@gmail.com \\ ${ }^{2}$ Department of Internal Medicine, Faculty of Medicine, Ege University, Izmir, Turkey; \\ drniyazi2002@yahoo.com, soner.duman@hotmail.com \\ ${ }^{3}$ Department of Chest Diseases, Faculty of Medicine, Ege University, Izmir, Turkey; sayiner2011@gmail.com
}

Received 9 January 2014; revised 9 February 2014; accepted 16 February 2014

Copyright (C) 2014 Pinar Tosun Tasar et al. This is an open access article distributed under the Creative Commons Attribution License, which permits unrestricted use, distribution, and reproduction in any medium, provided the original work is properly cited. In accordance of the Creative Commons Attribution License all Copyrights ¿ 2014 are reserved for SCIRP and the owner of the intellectual property Pinar Tosun Tasar et al. All Copyright @ 2014 are guarded by law and by SCIRP as a guardian.

\section{ABSTRACT}

Isoniazid is the most important antituberculosis medicine. Adverse effects are generally fever and rash. There are few case reports in the literature which identified high fever without rash associated with INH use. In this case report, we present a case with tuberculosis lymphadenitis and isoniazid-induced fever.

\section{KEYWORDS}

Isoniazid; Fever

\section{INTRODUCTION}

Isoniazid (INH) is the strongest drug among the present antituberculosis medications. It has a bacteriostatic effect on dormant bacilli and a bactericidal effect on the species which proliferate fast. It is the most important antituberculosis medicine because it is cheap, absorbed easily and able to penetrate in macrophages and caseous lesions. Adverse effects are few and they are identified in 2\% - 3\% of cases [1,2]. These are generally fever and rash [3]. Although concurrent presence of fever and rash makes the clinicians often consider the drug reaction, fever as a sole manifestation usually leads the physician to think that the infection is not yet under control. There are few case reports in the literature which identified high fever without rash associated with INH use. In this case report, we present one such case with tuberculosis lymphadenitis, in which INH had to be withdrawn from treatment.

\section{CASE}

82 years old female patient was admitted to the hospital due to weakness and fatigue on February, 2012. The patient had a history of partial mastectomy and radiotherapy six years ago for breast cancer and she had received anastrozole treatment for five years. Left supraclavicular lymphadenopathy (LAP) was determined on examination. The lymph node was excised and the pathological result was granulomatous lymphadenitis. No acid-fast bacteria were found, and polymerase chain reaction was determined as negative; however, no sample was sent to culture for M. tuberculosis. Antituberculosis therapy consisting of INH, ethambutol, pyrazinamide and rifampicin was started since the patient developed complaints of nausea, loss of appetite, weakness, weight loss. The therapy was discontinued on patient's will because of side effects such as nausea. The patient was admitted to Geriatrics department due to loss of appetite, weight loss and night sweating. On physical examination, the heart sounds were diminished and breath sounds were decreased in basal zones of both lungs. Biochemistry workup was normal except for a high sedimentation rate (60 $\mathrm{mm} / \mathrm{h}$ ). The chest $\mathrm{x}$-ray showed an increased cardiothoracic ratio. On thorax $\mathrm{CT}$, a calcified right upperparatracheal $(1.3 \mathrm{~cm})$ and non-calcified subcarinal lymph nodes were seen in the mediastinum. Pericardial effusion was two centimeters. On echocardiography, fibrinous pericardial fluid was determined around the right ventricle, with findings of pressure on a $2 \times 2 \mathrm{~cm}$ area. Pericardiosynthesis was carried out. Adenosine deaminase concentration of pericardial effusion was $26 \mathrm{U} / \mathrm{L}$ and ARB and M. tuberculosis (PCR) were negative. On direct examination, 100 leukocytes $/ \mathrm{mm}^{3}$ and abundant eryhtocytes were seen. The pathology result was reported as mixed inflammatory reaction. The tuberculin skin test was positive with an induration of $20 \times 20 \mathrm{~mm}$. In the light of symptoms of the patient, positive tuberculin reaction and 
pathology report of granulomatous lymphadenitis, antituberculosis therapy was started again (isoniazide 300, ethambutol 1250, pyrazinamide 1250, rifampicin 600 $\mathrm{mg}$ /day). Six hours after starting antituberculosis treatment, fever $\left(39^{\circ} \mathrm{C}\right)$ developed. No focal infection was determined on systemic examination. Although no infectious finding was determined, empirical piperacillin tazobactam was added to her treatment. On Day 4 of the treatment, no response could be obtained and, alanine and aspartate aminotransferase levels increased to 348 $\mathrm{U} / \mathrm{L}$ and $934 \mathrm{U} / \mathrm{L}$, respectively. Antituberculosis treatment and antibiotherapy were discontinued. Blood and urine cultures were negative. On peripheral smear, the ratio of eosinophils was 5\%. Immunoglobulin E (IgE) level was $189 \mathrm{IU} / \mathrm{mL}$ (normal range: less than100 IU/ $\mathrm{mL}$ ). N-acetylcysteine infusion was started based on preliminary diagnosis of toxic hepatitis for the patient who had normal viral hepatitis serology and abdomen ultrasound scan. On Day 7 of the follow-up, the patient had normal liver function tests and fever was not observed within this period. It was decided to start antituberculosis drugs one by one again. The hepatotoxic drugs were to be given at low doses first and the dose would be increased to normal levels if no adverse event developed within two days. Thus, ethambutol and rifampicin were first started at doses of $1250 \mathrm{mg}$ and $300 \mathrm{mg}$ per day, respectively, and the dose of rifampicin was increased to $600 \mathrm{mg}$ three days later. No fever developed, no increase in hepatic enzyme levels was observed. However, she developed a fever reaching $39^{\circ} \mathrm{C} 10$ hours after adding INH $100 \mathrm{mg} /$ day to her treatment while her liver function test results remained normal. High fever was attributed to INH and this drug was stopped. Later, pyrazinamide 500 $\mathrm{mg} /$ day was added to her treatment and the dose was later increased to $1250 \mathrm{mg} /$ day without any adverse event. All symptoms improved over the next two weeks and no fever was observed. On Day 14 of triple antituberculosis therapy, her liver function test results remained normal On control echocardiography, regression was found in fibrin and liquid content of pericardial effusion.

\section{DISCUSSION}

Frequent side effects related to INH are rash, hepatitis, arthralgia and high fever [1].

High fever related to INH was firstly identified by Krasnitz in 1953 [4]. Christianson CS et al. observed in a series of 1744 patients that 22 patient could not tolerate INH treatment and the most common side effect was fever (59\%) [5]. In a series of 814 cases examined by Dutt et al., rate of fever was 1 percent [2]. High fever related to INH was generally observed during multi-drug therapy [6,7]. Only one case who received INH chemoprophylaxis was reported to develop fever [8]. In our case, the patient was receiving the standard four-drug regimen when fever first occurred.

The mechanism is not clear but it is thought that it may be related with an immunopathological process associated with antibody formation. In a study conducted by Onborne, RK et al., high fever related to INH was seen to be more frequent in people allergic to p-aminosalicylic acid, streptomycin and penicillin [7]. However, our case had no allergy to a particular drug.

Our case was characterized with high fever up to $39^{\circ} \mathrm{C}$ which was noted 6 hours after the administration of antituberculosis drugs, including INH. Considering cases of Dutt et al., fever reaction developed between Day 10 and Day 20 of treatment. When the drug was discontinued and started again, fever response was seen in the first 2 10 hours. In 1977 in the case report of two cases, Davis RS et al. observed fever and myalgia within 8 - 14 days, and when the treatment was discontinued and started again, fever $\left(40^{\circ} \mathrm{C}\right)$ was seen within two and three hours [6].

The diagnosis of drug-induced fever is based on clinical observation. Serology and skin tests have no place in the diagnosis [9].

Peripheral eosinophilia and high levels of IgE may be seen in drug-induced high fever [10]. In our patient, a moderate elevation of eosinophilia (5\%) and IgE levels were determined. As infection could not be ruled out when fever first developed, antibiotic treatment was started with no response. The fever only subsided after the discontinuation of all antimicrobials following the rise in hepatic enzymes.

The diagnosis of drug-induced fever was thus made through clinical observation. In the follow up, fever was seen again, without any concomitant increase in liver enzymes, after INH was added to treatment.

Fever and rash have commonly been observed together in the reported cases, but in our case there was no rash $[10,11]$. In the absence of any rash, the physician dealing with high fever is usually inclined to consider infectious reasons first and to start antibiotherapy. No rash was observed in the series examined by Eija-Riitta Salomaa et al. either, and these authors also started empirical antibiotic treatment before the diagnosis of druginduced fever was made [12].

In the case study, we aimed to draw the attention of the physician to fever reaction without rash resulting from INH. Drug-induced fever is a reaction that can cause mortality and morbidity $[6,13]$. Clinical suspicion is crucial for diagnosis.

\section{REFERENCES}

[1] Dutt, A.K., Moers, D. and Stead, W.W. (1983) Undesirable side effects of isoniazid and rifampin in largely 
twice-weekly short-course chemotherapy for tuberculosis. American Review of Respiratory Disease, 128, 419-424.

[2] Berte, S.J., Dimase, J.D. and Christianson, C.S. (1964) Isoniazid, para-aminosalicylic acid, and streptomycin intolerance in 1744 patients. An analysis of reactions to single drugs and drug groups plus data on multiple re- actions, type and time of reactions, and desensitization. American Review of Respiratory Disease, 90, 598-606.

[3] Goldman, A.L. and Braman, S.S. (1972) Isoniazid: A review with emphasis on adverse effects. Chest, 62, 7177. http://dx.doi.org/10.1378/chest.62.1.71

[4] Krasnitz, A. (1953) Drug fever due to administration of isoniazid. American Review of Tuberculosis, 68, 249-252.

[5] Berte, S.J., Dimase, J.D. and Christianson, C.S. (1964) Isoniazid, para-aminosalicylic acid and streptomycin intolerance in 1744 patients. American Review of Respiratory Disease, 90, 598-606.

[6] Davis, R.S. and Stoler, B.S. (1977) Febrile reactions to INH. The New England Journal of Medicine, 297, 337. http://dx.doi.org/10.1056/NEJM197708112970616

[7] Haber, E. and Osborne, R.K. (1959) Icterus and febrile reactions in response to isonicotinic acid hydrazine; report of two cases and review of the literature. The New England Journal of Medicine, 260, 417-420.
http://dx.doi.org/10.1056/NEJM195902262600904

[8] Jacobs, N.F. and Thompson, S.E. (1976) Spiking fever from isoniazid simulating a septic process. The Journal of the American Medical Association, 238, 1759-1760.

[9] Lipsky, B.A. and Hirschmann, J.V. (1981) Drug fever. The Journal of the American Medical Association, 245, 851-854. http://dx.doi.org/10.1001/jama.1981.03310330041024

[10] Demeter, S.L., Ahmad, M. and Tomashefski, J.F. (1979) Drug-induced pulmonary disease. Part I. Patterns of response. Cleveland Clinic Quarterly, 46, 89-99. http://dx.doi.org/10.3949/ccjm.46.3.89

[11] Fresresneau, M., Boumard, B.B. and Le Brizaut, Y. (1953) L'infiltrat pulmonaire avec éosinophilie au cours du traitement par l’isoniazide. La Presse Médicale, 63, 1454.

[12] Salomaa, E.-R., Ruokonen, E.-L. and Tevola, K. (1990) Pulmonary infiltrates and fever induced by isoniazid. Postgraduate Medical Journal, 66, 647-664. http://dx.doi.org/10.1136/pgmj.66.778.647

[13] Dasta, J.F., Prior, J.A. and Kurzrok, S. (1979) Isoniazid induced fever. Chest, 75, 196-197. http://dx.doi.org/10.1378/chest.75.2.196 